Tohoku J. Exp. Med., 2004, 202, 283-294

\title{
The Effects of Vagal Stimulation on Laryngeal Vascular Resistance and Intraluminal Pressure in the Dog
}

\author{
Nermin Karaturan Yelmen, Gülderen Şahin and Tülin Oruç \\ University of Istanbul, Cerrahpaşa Medical School, Department of Physiology, \\ Istanbul, Turkey
}

Yelmen, N.K., ŞAhin, G. and Oruç, T. The Effects of Vagal Stimulation on Laryngeal Vascular Resistance and Intraluminal Pressure in the Dog. Tohoku J. Exp. Med., 2004, 202 (4), 283-294 — In anaesthetized dogs (sodium pentobarbitone $30 \mathrm{mg} / \mathrm{kg}$, i.v.) laryngeal vascular resistance was measured by unilateral perfusion at constant flow of the branch of the cranial superior thyroid artery that supplies the larynx. Arterial perfusion was at constant flow and inflow pressure was divided by flow to give laryngeal vascular resistance $\left(\mathrm{R}_{\mathrm{LV}}\right)$. Intraluminal laryngeal pressure $\left(\mathrm{P}_{\mathrm{L}}\right)$ and systemic arterial blood pressure (BP) were also measured. Stimulation (20 $\mathrm{V}, 20 \mathrm{~Hz}, 0.2$ milliseconds) of the central end of cervical vagus caused an increase in $\mathrm{R}_{\mathrm{LV}}(+22.9 \pm 6.1 \%)$ and a decrease in $\mathrm{P}_{\mathrm{L}}(-12.1 \pm 4.4 \%)$. Stimulation $(10 \mathrm{~V}, 10 \mathrm{~Hz}$, 0.2 milliseconds) of the central end of the recurrent laryngeal nerve (RLN) reduced $\mathrm{R}_{\mathrm{LV}}(-3.4 \pm 0.8 \%)$ and $\mathrm{P}_{\mathrm{L}}(-7.5 \pm 4.1 \%)$. Stimulation of the peripheral end of the RLN decreased $\mathrm{R}_{\mathrm{LV}}(-7.1 \pm 1.9 \%)$ and increased $\mathrm{P}_{\mathrm{L}}(+21.6 \pm 7.7 \%)$. Stimulation of the central end of the superior laryngeal nerve $(\mathrm{SLN})$ increased $\mathrm{R}_{\mathrm{LV}}(+17.9 \pm 3.2 \%)$ and $\mathrm{P}_{\mathrm{L}}$ $(+59.8 \pm 2.7 \%)$, whereas stimulation of the peripheral end of the SLN decreased $\mathrm{R}_{\mathrm{LV}}$ $(-4.8 \pm 1.6 \%)$ and $\mathrm{P}_{\mathrm{L}}(-4.1 \pm 2.4 \%)$. After treatment with $\alpha$-adrenoreceptor antagonist phentolamine $(0.5 \mathrm{mg} / \mathrm{kg}$, i.v.), stimulation of the central end of cervical vagus nerve reduced $\mathrm{R}_{\mathrm{LV}}$ by $25 \%$ and decreased $\mathrm{BP}$. Phentolamine caused a decrease in BP and reduced the magnitude of increase in $R_{L V}$ in response to stimulation of central end of SLN. After atropine sulphate $(0.5-2.0 \mathrm{mg} / \mathrm{kg}$, i.v. $)$, the stimulation of both central and peripheral ends of RLN reduced $R_{\mathrm{LV}}$. The decrease in $\mathrm{R}_{\mathrm{LV}}$ during stimulation of peripheral end of SLN was reduced by atropine. Thereafter, pancuronium bromide $(0.06-0.1 \mathrm{mg} / \mathrm{kg}$, i.v.) was given and dogs were artifically ventilated. After paralyzed, stimulation of the central end of the SLN decreased $\mathrm{R}_{\mathrm{LV}}$ $(+26.0 \pm 4.5 \%)$ but produced no change in $\mathrm{P}_{\mathrm{L}}$. It is concluded that parasympathetic motor fibers in the RLN and SLN are effective for the laryngeal vascularity and non-adrenergic system may be responsible for laryngeal vasoconstriction.

laryngeal vasculature; vagal stimulation; phentolamine; atropine

(C) 2004 Tohoku University Medical Press

Received November 18, 2003; revision accepted for publication February 25, 2004.

Address for reprints: Prof. Dr. Gülderen Şahin, Istanbul University, Cerrahpaşa Medical School, Department of Physiology, Istanbul, Turkey.

e-mail: sahing@istanbul.edu.tr 
The larynx is a highly reflexogenic area and stimulation with mechanical and chemical stimuli results in a number of protective reflexes. Investigators have used anatomical, behavioral and neurophysiological techniques to examine the receptors responsible for initiating these reflex responses (Sant'Ambrogio and Sant' Ambrogio 1996; Shiba et al. 1997; Bradley 2000; Widdicombe 2001). The pharmachological and neural control of laryngeal calibration have been studied frequently (Brouillette and Thach 1979; Jodkowski and Berger 1988; Shiba et al. 1997; Widdicombe 2001). As is well known, stimulation of the mechanosensitive, irritan and chemosensitive endings of the larynx cause respiratory, cardiovascular and broncomotor reflexes. Their clinical importance in sleep apneas, sudden infant death syndrome and gastroesophageal aspiration syndrome have been studied (Widdicombe 1986a; Sataloff et al. 1993). In contrast, the chemical and neural reflex control of laryngeal vasculature has not been studied.

The afferent and efferent innervation of larynx are mediated by superior laryngeal nerve and recurrent laryngeal nerve. The laryngeal arteries are supplied from the systemic circulation and drain entirely into systemic veins. We have recently developed a model of perfused laryngeal vasculature and used it to study the pharmachological and neural control of the laryngeal circulation (Şahin and Güner 1992; Güner and Şahin 1993). Our previous study has suggested that stimulation of respiration by hypoxia and hypercapnia increases laryngeal vascular resistance and decreases laryngeal intraluminal pressure. Laryngeal vasoconstrictor response to hypoxia and hypercapnia is produced by the effect of hypoxia and $\mathrm{CO}_{2}$ on the central nervous system and the resultant increase in sympathetic discharge to the larynx (Şahin et al. 1999).

It is well known that nasal, tracheobronchial circulation are mainly under sympathetic vasoconstrictor control (Godden 1990; Widdicombe 1990). Sympathetic nerve stimulation increases their vascular resistance. Although the role of parasympathetic and sympathetic nerves to the laryngeal vascular bed are not well established, the stimulation of superior laryngeal nerve causes nasal and tracheal vasodilatation (Laitinen et al. 1987a; Dylewska et al. 1993). This response can be blocked by muscarinic agents such as atropine and may be caused by acetylcholine and metacholine (Laitinen et al. 1987b). On the other hand, Laitinen et al. (1987a) suggested that vasodilatation caused by parasympathetic nerve stimulation in nose and trachea after atropine administration, may be mediated by the release of neuropeptides such as VIP. Recent studies in which the role and distribution of neurotransmitters and neuromodulators are investigated, suggest that NPY, VIP, NOS-1 and CGRP take an important part in the regulation of laryngeal blood flow (Hisa et al. 1999; Lyon 2000).

It was shown that the parasympathetic innervation of the dog trachea is partly in the SLN, stimulation of which causes vasodilatation on both sides (Laitinen et al. 1987a). On the other hand, stimulation of the central end of a vagus nerve causes tracheal vasoconstriction, systemic hypertension and smooth muscle contraction via impulses came from the cardiac nerves not the pulmonary or abdominal branches of the vagus (Şahin et al. 1987a). Whether or not parasympathetic cholinergic fibers to the laryngeal vasculature can cause relaxation is more controversial, and in general histological studies do not support a close cholinergic innervation of the vessels (Laitinen et al. 1987b). Furthermore, the exact motor pathways have not been identified.

For this reason, in this study, we have investigated the effects of the stimulation of central (afferent) and peripheral (efferent) ends of the vagus and its branches on laryngeal vascular resistance. We have also attemped to determine whether these vasodilatator or vasoconstrictor responses are of parasympathetic or of sympathetic origin by using adrenergic and cholinergic antagonists. Further we aimed to investigate a relation between changes in laryngeal vascular resistance and laryngeal muscular tone. 


\section{Material ANd Methods}

The experiments were carried out on twelve dogs of both sexes with a mean weight of $24.6 \pm 0.7$ $\mathrm{kg}$. Animals were anaesthetized with sodium pentobarbitone (initial dose, $30 \mathrm{mg} / \mathrm{kg}$, i.v.: thereafter $5 \mathrm{mg} / \mathrm{kg} / \mathrm{h}$, i.v.) to produce a steady level of anaesthesia. Supplementary doses of anaesthetic were given if mean arterial blood pressure increased initial value, respiratory frequency increased above $25 \mathrm{~min}^{-1}$, irregular fluctuations in heart rate. Animals were euthanized by i.v. injection of an overdose $(500 \mathrm{mg} / \mathrm{kg}$, i.v.) of sodium pentobarbitone that caused rapid and irreversible cardiac arrest. Our protocol and methods were approved by the Animal Care and Use Committee of the Laboratory Animal Service of the University of Istanbul, Turkey. Catheters were inserted into the femoral arteries during the operation. One catheter was connected to a pressure transducer for the measurement of systemic arterial blood pressure and the other was used to supply blood to the laryngeal perfusion circuit. Another catheter was inserted into the left femoral vein to give heparin and supplemental doses of anaesthetic. A low cervical tracheostomy was performed, and a tracheal cannula was inserted. Recurrent, superior laryngeal nerves and the cervical portion of the vagus nerve were isolated. In all experiments a thin-walled balloon catheter was inserted into the larynx and filled with 2-5 $\mathrm{ml}$ of saline to give an initial intraluminal laryngeal pressures usually 5-10 mmHg.

Nerves were stimulated via bipolar platinum electrodes with a Palmer stimulator. Stimulus duration was 0.2 milliseconds. Strength was $20 \mathrm{~V}$ for the vagus and $10 \mathrm{~V}$ for other nerves, and frequencies were 10-20 Hz. Stimulus burst durations were 30 seconds. If maximum response was obtained earlier than 30 seconds then the stimulation was ended. However no maximum response was obtained in a duration of less than 25 seconds.

\section{Measurement of laryngeal vascular resistance}

Laryngeal vascular perfusion was performed by a technique modified from a tracheal vascular perfusion model which was previously described (Şahin et al. 1987a, b and c). On both sides of the trachea, the common carotid arteries were isolated at the level of the superior thyroid artery and superior laryngeal arteries. Superior laryngeal arteries were tied off bilaterally. On the left side, the branch of the superior thyroid that supplies the larynx was tied off. On the right side, the branches of the superior thyroid artery to skeletal muscle, trachea and thyroid gland were tied off. On this side the branch of the superior thyroid artery that supplies the larynx was left intact. Both caudal and cranial to the superior thyroid artery, the common carotid artery was tied off. The isolated and artifically perfused segment of the common carotid artery was bypassed by a plastic tube so that carotid sinus pressure and blood flow to the brain was maintained (Fig. 1).

The isolated segment of the common carotid artery was perfused by blood from the femoral artery using a reservoir and peristaltic pump. Thus perfusion of the larynx on the right side was provided. The perfusion pressure was measured with pressure transducers from a point between the pump and the carotid arterial catheter. Each perfusion pump flow rate was initially adjusted so that mean laryngeal perfusion pressure was $\sim 120$ $\mathrm{mmHg}$ close to mean arterial pressure. In order to determine the changes in laryngeal muscle tone, intraluminal laryngeal pressure was recorded (Grass PT5 volumetric pressure transducer Statam Laboratories, Inc., Hato Rey, Puerto Rico) to indicate the changes in calibration of the laryngeal orifice. As is well known, changes in calibration of the laryngeal orifice is brought about by changes in laryngeal muscle tone. A fall in pressure indicates widening of the orifice, which in turn indicates a decrease of air-flow resistance. Each dog was injected with heparin $(500 \mathrm{U} / \mathrm{kg}$ i.v.). The distribution of perfusion was tested by close arterial injection of Evans Blue. Laryngeal vascular resistance $\left(\mathrm{R}_{\mathrm{LV}}\right)$ was calculated from the determined values of perfusion pressure (inflow pressure, Rt P. P) and flow rate (usually 13 

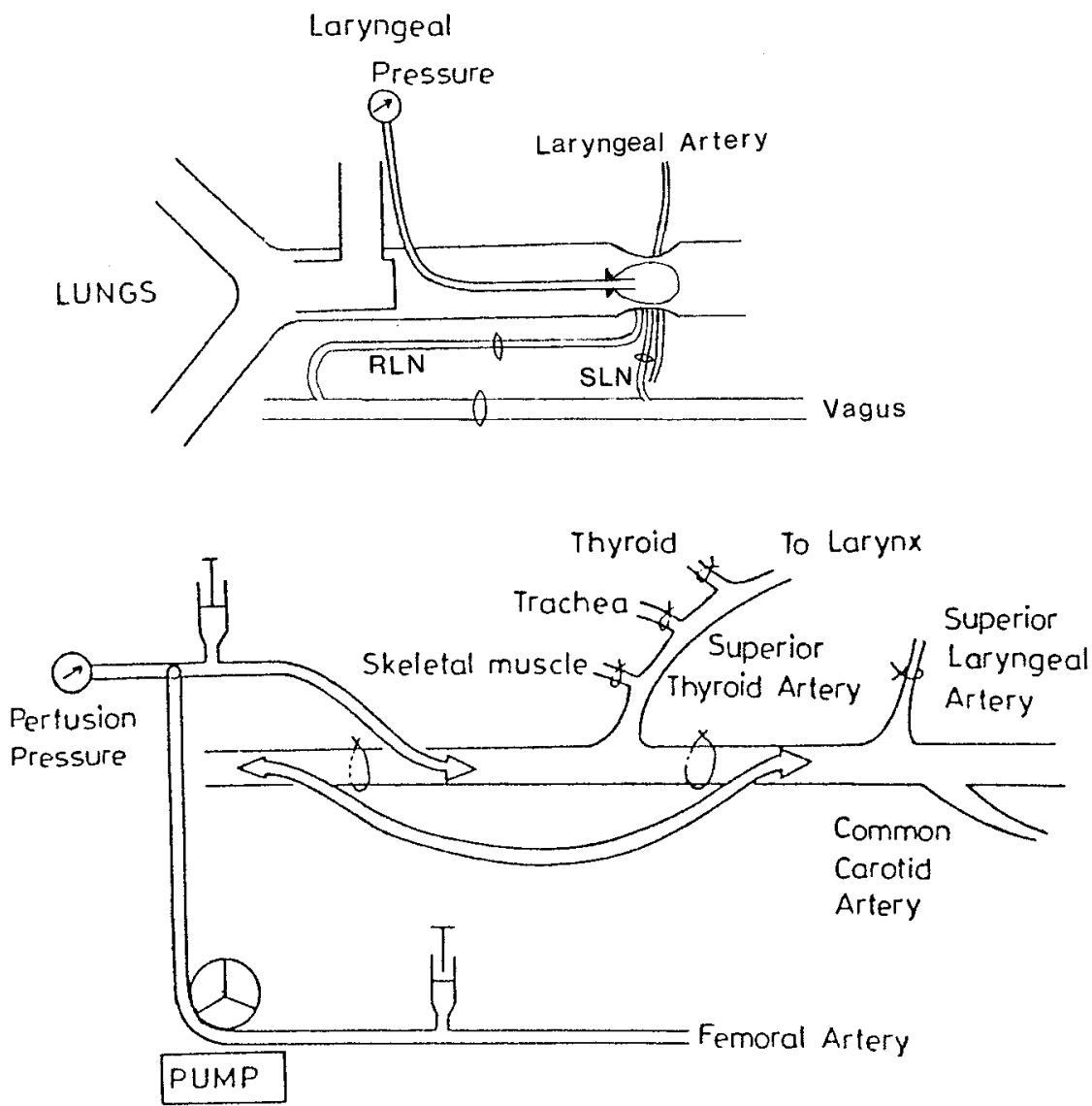

Fig. 1. Experimental arrangement caudal tracheal cannula for ventilation of lungs and ballon inserted larynx to indicated changes larynx muscle tone, and the nerves of larynx. O indicates the points of stimulation and cutting of the nerves perfused segment of common carotid artery from which superior thyroid artery aries. All its branches have been tied off except that to larynx.

$\mathrm{ml} . / \mathrm{min})$.

\section{Experimental protocol}

The laryngeal vascular perfusion pressure (Rt P. P), intraluminal laryngeal pressure $\left(\mathrm{P}_{\mathrm{L}}\right)$ and systemic arterial blood pressure (BP) were recorded on the polygraph (Grass Model 7, West Warwick, RI, USA) by means of pressure transducers. The nerves that were stimulated were cervical vagus nerve (vagosympathetic trunk), recurrent laryngeal nerve (RLN), and superior laryngeal nerve (SLN) respectively. The exact level of vagal stimulation was midcervical which corresponds to the point $4 \mathrm{~cm}$. below the point where superior laryngeal nerve leaves the vagus nerve. Each nerve was cut, central (afferent) and periph- eral (efferent) endings were stimulated separately. Electrical stimulus frequencies were increased until clear vascular responses were seen, but they were never $>20 \mathrm{~Hz}$. Firstly, vagus nerve was cut bilaterally. After stimulation of both ends of right vagus, firstly RLN and then SLN were cut separately and stimulated respectively. Only the SLN was left intact on the counter-lateral side. During the stimulation procedures, it was waited for the $\mathrm{R}_{\mathrm{LV}}, \mathrm{P}_{\mathrm{L}}$ and $\mathrm{BP}$ values to settle down near the initial values (approximately 5-10 minutes) after each stimulation.

As a result of the nerve stimulation, the nature of the responses (whether parasympathetic or sympathetic) were investigated with atropine sulphate $(0.5-2.0 \mathrm{mg} / \mathrm{kg}$, i.v. muscarinic antagonist) 
and phentolamine $(0.5 \mathrm{mg} / \mathrm{kg}$, i.v. $\alpha$-adrenoceptor antagonist). After administration of the antagonists, indicated nerves were again stimulated. In order to prevent the effects of somatic nerves on laryngeal responses and to prevent the effects of change of laryngeal muscle tone on laryngeal vascular resistance, the dogs were paralyzed with an intravenous injection of pancuronium bromide $(0.06-0.1 \mathrm{mg} / \mathrm{kg}$, i.v.) and ventilated with a tidal volume of $10-15 \mathrm{mg} / \mathrm{kg}$ at a constant rate of $14-28$ breaths $\min ^{-1}$. All biochemicals are supplied from Sigma.

\section{Statistical analysis}

Control values of the $\mathrm{R}_{\mathrm{LV}}, \mathrm{P}_{\mathrm{L}}$ and $\mathrm{BP}$ were expressed as means \pm S.D. error of the mean. The control values of the indicated parameters were taken as $100 \%$ and percentage values of variables were calculated. The statistical significance of the change in responses observed after the electrical stimulation with the initial values were analyzed with Wilcoxon-Matched Pairs test. The statistical significance of the percent changes before and after atropine and phentolamine administration were analyzed with Mann-Whitney's
U-test. To compare $\mathrm{R}_{\mathrm{LV}}$ and $\mathrm{P}_{\mathrm{L}}$ before and after cutting vagal nerve and its branches, the analysis of variance (ANOVA) were used. Differences were taken to be significant when $p<0.05$.

\section{Results}

\section{Control values}

At the start of the experiments the initial values (mean \pm S.E.) of $R_{L v}, P_{L}$ and BP were $9.3 \pm 0.4$ $\mathrm{mmHg} \cdot \mathrm{ml}^{-1} \mathrm{~min}, 9.7 \pm 1.0 \mathrm{mmHg}$ and $109.8 \pm 5.2$ $\mathrm{mmHg}$ respectively. After cutting of vagus, RLN and SLN, there was no significant difference in the initial values of $R_{L v}(9.2 \pm 0.5,8.8 \pm 0.7,8.4 \pm 0.4$ respectively). On the other hand, after cutting of vagus and RLN there were significant increases in $\mathrm{P}_{\mathrm{L}}(13.1 \pm 1.1, p<0.01 ; 15.0 \pm 1.9, p<0.05)$ and $\mathrm{BP}$ $(118.3 \pm 6.3, p<0.05 ; 118.7 \pm 4.1, p<0.05)$ respectively.

Stimulation of cervical vagus. Stimulation of the intact vagus nerve at cervical level (vagosympathetic trunk) caused a significant decrease in $\operatorname{R}_{\mathrm{LV}}(-5.8 \pm 3.2 \%, p<0.01)$ (Table 1). The initial decrease in $R_{L V}$ which took place 5 seconds after the beginning of vagal stimulation was followed by an increase $(+15.4 \pm 2.8 \%, p<0.01)$. The minute

TABLE 1. Effects of vagal stimulation on $R_{L V}, P_{L}, B P$ of dogs in the indicated experimental phases

\begin{tabular}{|c|c|c|c|c|c|c|}
\hline \multirow{2}{*}{$\begin{array}{l}\text { Experimental phase } \\
\qquad(n=12)\end{array}$} & \multicolumn{2}{|l|}{$\mathrm{R}_{\mathrm{LV}}$} & \multicolumn{2}{|c|}{$\mathrm{P}_{\mathrm{L}}$} & \multicolumn{2}{|c|}{$\mathrm{BP}$} \\
\hline & $\begin{array}{c}\text { Control } \\
\left(\mathrm{mmHg} \cdot \mathrm{ml}^{-1} \cdot \mathrm{min}\right)\end{array}$ & $\begin{array}{c}\text { Change } \\
(\%)\end{array}$ & $\begin{array}{l}\text { Control } \\
(\mathrm{mmHg})\end{array}$ & $\begin{array}{c}\text { Change } \\
(\%)\end{array}$ & $\begin{array}{l}\text { Control } \\
(\mathrm{mmHg})\end{array}$ & $\begin{array}{l}\text { Change } \\
(\%)\end{array}$ \\
\hline $\begin{array}{l}\text { Vagi intact } \\
\text { (Vagi cut) }\end{array}$ & $9.3 \pm 0.4$ & $\begin{array}{r}-5.8 \pm 3.2^{\mathrm{b}} \\
+15.4 \pm 2.8^{\mathrm{b}}\end{array}$ & $9.7 \pm 1.0$ & $-7.1 \pm 7.2$ & $109.8 \pm 5.2$ & $+13.5 \pm 2.3^{b}$ \\
\hline Central end & $9.2 \pm 0.5$ & $+22.9 \pm 6.1^{\mathrm{c}}$ & $13.1 \pm 1.1^{\mathrm{g}}$ & $-12.1 \pm 4.4^{\mathrm{a}}$ & $118.3 \pm 6.3^{\mathrm{f}}$ & $+14.1 \pm 2.8^{\mathrm{b}}$ \\
\hline Peripheral end & $8.8 \pm 0.8$ & $+2.2 \pm 15.2$ & $10.9 \pm 1.4$ & $+36.7 \pm 6.4^{\mathrm{b}}$ & $119.6 \pm 4.2$ & $-11.6 \pm 3.2^{\mathrm{b}}$ \\
\hline $\begin{array}{l}\text { Atropine (i.v.) } \\
+ \text { Central end }\end{array}$ & $9.0 \pm 0.4$ & $+27.1 \pm 5.4^{\mathrm{c}}$ & $12.9 \pm 1.3$ & $-12.8 \pm 5.3$ & $117.9 \pm 5.9$ & $+20.5 \pm 2.5^{\mathrm{c}, \mathrm{d}}$ \\
\hline $\begin{array}{l}\text { Phentolamine (i.v.) } \\
+ \text { Central end }\end{array}$ & $9.5 \pm 0.7$ & $+16.5 \pm 2.9^{b}$ & $12.8 \pm 0.9$ & $-11.6 \pm 3.8^{a}$ & $120.6 \pm 8.5$ & $-8.6 \pm 2.6^{\mathrm{b}}$ \\
\hline
\end{tabular}

Values are mean \pm S.E. of dogs.

$\mathrm{R}_{\mathrm{LV}}$, Laryngeal vascular resistance; $\mathrm{P}_{\mathrm{L}}$, Intraluminal blood pressure; $\mathrm{BP}$, Mean arterial blood pressure. ${ }^{\mathrm{a}} p<0.05,{ }^{\mathrm{b}} p<0.01,{ }^{\mathrm{c}} p<0.001$ for change compared with zero effect. drug.

${ }^{\mathrm{d}} p<0.01,{ }^{\mathrm{e}} p<0.001$ for response of stimulation after drug compared with response of stimulation without

${ }^{\mathrm{f}} p<0.05,{ }^{\mathrm{g}} p<0.01$ indicates statistical significance of the difference between the response of cut RLN and intact RLN. 
A
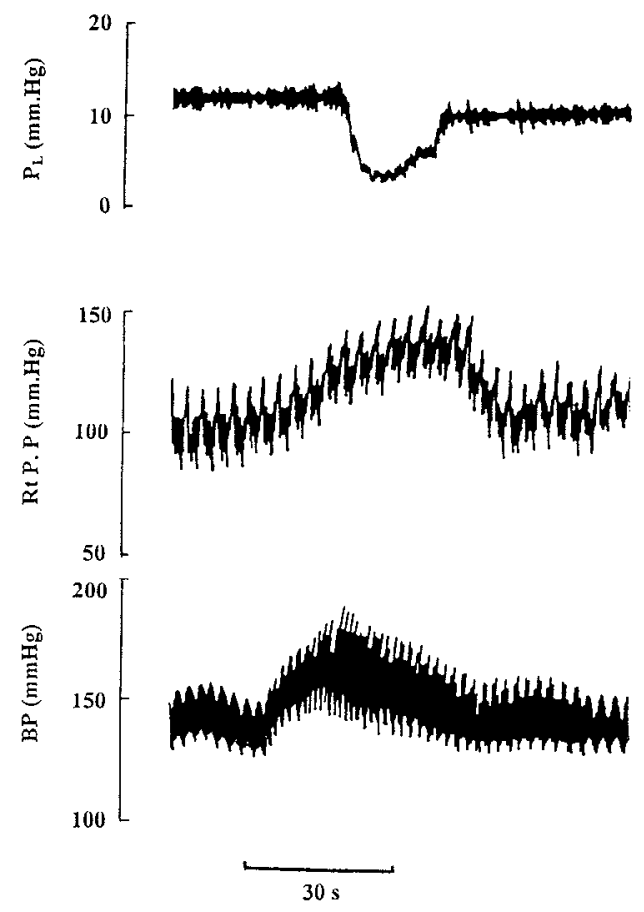

B
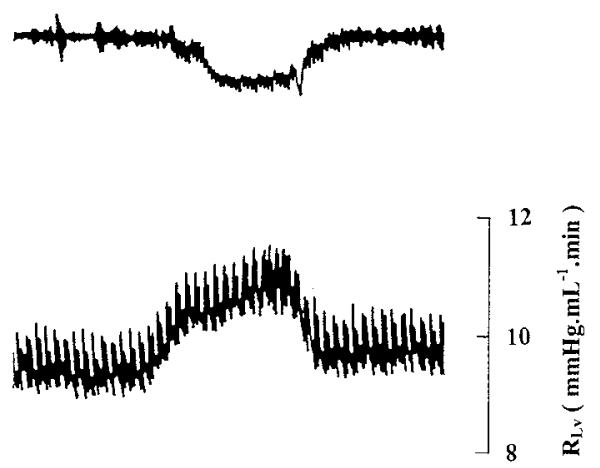

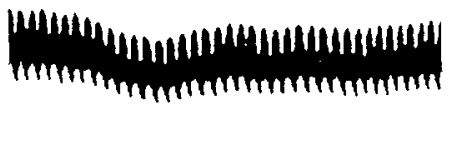

Fig. 2. Responses to stimulation of central cut end of right vagus nerve before (A) and after (B) phentolamine $(0.5 \mathrm{mg} / \mathrm{kg}$, i.v. $)$ injection. From top, traces represent intraluminal laryngeal pressure $\left(\mathrm{P}_{\mathrm{L}}\right)$, right laryngeal perfusion pressure (Rt P. P) and blood pressure (BP). Signal bar, stimulus applied for 30 seconds.

TABLE 2. Effects of recurrent laryngeal nerve (RLN) stimulation on $R_{L V}, P_{L}$ and BP of dogs in the indicated experimental phases

\begin{tabular}{|c|c|c|c|c|c|c|}
\hline \multirow{2}{*}{$\begin{array}{l}\text { Experimental phase } \\
\qquad(n=12)\end{array}$} & \multicolumn{2}{|c|}{$\mathrm{R}_{\mathrm{LV}}$} & \multicolumn{2}{|c|}{$\mathrm{P}_{\mathrm{L}}$} & \multicolumn{2}{|c|}{$\mathrm{BP}$} \\
\hline & $\begin{array}{c}\text { Control } \\
\left(\mathrm{mmHg} \cdot \mathrm{ml}^{-1} \cdot \mathrm{min}\right)\end{array}$ & $\begin{array}{c}\text { Change } \\
(\%)\end{array}$ & $\begin{array}{l}\text { Control } \\
(\mathrm{mmHg})\end{array}$ & $\begin{array}{c}\text { Change } \\
(\%)\end{array}$ & $\begin{array}{l}\text { Control } \\
(\mathrm{mmHg})\end{array}$ & $\begin{array}{c}\text { Change } \\
(\%)\end{array}$ \\
\hline $\begin{array}{l}\text { RLN intact } \\
\text { (RLN cut) }\end{array}$ & $9.4 \pm 0.5$ & $-4.8 \pm 1.9^{\mathrm{a}}$ & $12.2 \pm 1.6$ & $+15.0 \pm 5.0^{\mathrm{b}}$ & $115.9 \pm 8.2$ & $-2.2 \pm 5.9$ \\
\hline Central end & $8.8 \pm 0.7$ & $-3.4 \pm 0.8^{\mathrm{a}}$ & $15.0 \pm 1.9^{\mathrm{e}}$ & $-7.5 \pm 4.1^{\mathrm{a}}$ & $118.7 \pm 4.1^{\mathrm{e}}$ & $-1.5 \pm 3.4$ \\
\hline $\begin{array}{l}\text { Atropine (i.v.) } \\
+ \text { Central end }\end{array}$ & $8.1 \pm 0.6$ & $-0.1 \pm 0.7^{\mathrm{d}}$ & $13.9 \pm 0.5$ & $-1.1 \pm 0.2^{\mathrm{d}}$ & $118.9 \pm 5.2$ & $-0.9 \pm 4.5$ \\
\hline Peripheral end & $8.5 \pm 0.2$ & $-7.1 \pm 1.9^{b}$ & $13.5 \pm 1.5$ & $+21.6 \pm 7.7^{\mathrm{a}}$ & $116.1 \pm 9.1$ & $-2.9 \pm 2.3$ \\
\hline $\begin{array}{l}\text { Atropine (i.v.) } \\
+ \text { Peripheral end }\end{array}$ & $8.3 \pm 0.3$ & $-1.2 \pm 0.4^{\mathrm{c}}$ & $13.8 \pm 1.3$ & $+22.9 \pm 6.7^{\mathrm{a}}$ & $120.3 \pm 6.1$ & $+1.1 \pm 3.4^{\mathrm{c}}$ \\
\hline
\end{tabular}

Values are mean \pm s.E. of dogs.

$\mathrm{R}_{\mathrm{LV}}$, Laryngeal vascular resistance; $\mathrm{P}_{\mathrm{L}}$, Intraluminal blood pressure; $\mathrm{BP}$, Mean arterial blood pressure. ${ }^{\mathrm{a}} p<0.05,{ }^{\mathrm{b}} p<0.01$, for change compared with zero effect.

${ }^{c} p<0.05,{ }^{d} p<0.01$, for response of stimulation after drug compared with response of stimulation without drug.

${ }^{\mathrm{f}} p<0.05$, indicates statistical significance of the difference between the responses of cut RLN and intact RLN. 
A
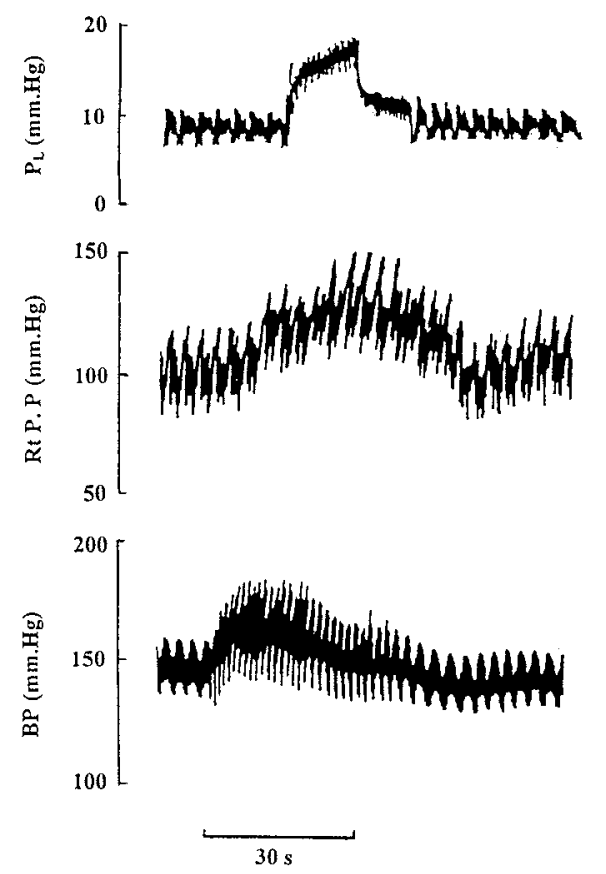

B
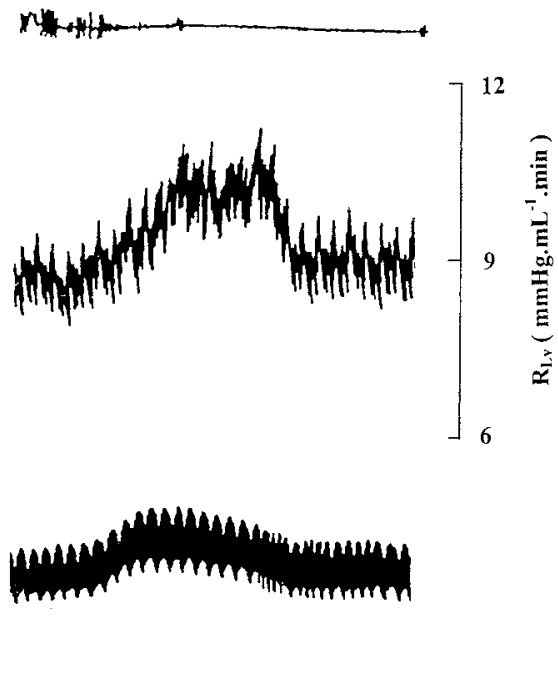

Fig. 3. Responses to stimulation of central cut end of right superior laryngeal nerve before (A) and after (B) Pancronium Bromide (0.06-0.1 mg/kg, i.v.) injection. From top, traces represent intraluminal laryngeal pressure $\left(\mathrm{P}_{\mathrm{L}}\right)$, right laryngeal perfusion pressure $(\mathrm{Rt} \mathrm{P} . \mathrm{P})$ and blood pressure (BP). Signal bar, stimulus applied for 30 seconds.

TABLE 3. Effects of superior laryngeal nerve (SLN) stimulation on $R_{L V}, P_{L}$ and BP of dogs in the indicated experimental phases

\begin{tabular}{|c|c|c|c|c|c|c|}
\hline \multirow{2}{*}{$\begin{array}{l}\text { Experimental phase } \\
\qquad(n=12)\end{array}$} & \multicolumn{2}{|c|}{$\mathrm{R}_{\mathrm{LV}}$} & \multicolumn{2}{|c|}{$\mathrm{P}_{\mathrm{L}}$} & \multicolumn{2}{|c|}{$\mathrm{BP}$} \\
\hline & $\begin{array}{c}\text { Control } \\
\left(\mathrm{mmHg} \cdot \mathrm{ml}^{-1} \cdot \mathrm{min}\right)\end{array}$ & $\begin{array}{l}\text { Change } \\
(\%)\end{array}$ & $\begin{array}{l}\text { Control } \\
(\mathrm{mmHg})\end{array}$ & $\begin{array}{c}\text { Change } \\
(\%)\end{array}$ & $\begin{array}{l}\text { Control } \\
(\mathrm{mmHg})\end{array}$ & $\begin{array}{c}\text { Change } \\
(\%)\end{array}$ \\
\hline $\begin{array}{l}\text { SLN intact } \\
\text { (SLN cut) }\end{array}$ & $8.8 \pm 0.3$ & $+13.6 \pm 15.2^{\mathrm{b}}$ & $12.6 \pm 1.3$ & $+56.7 \pm 10.2^{c}$ & $113.5 \pm 9.7$ & $+12.5 \pm 4.6^{\mathrm{a}}$ \\
\hline Central end & $8.4 \pm 0.4$ & $+17.9 \pm 3.2^{\mathrm{c}}$ & $11.1 \pm 1.0$ & $+59.8 \pm 2.7^{\mathrm{b}}$ & $112.3 \pm 5.8$ & $+13.7 \pm 3.3^{\mathrm{a}}$ \\
\hline Peripheral end & $8.8 \pm 0.2$ & $-4.8 \pm 1.6^{\mathrm{b}}$ & $14.7 \pm 2.1$ & $-4.1 \pm 2.4^{\mathrm{a}}$ & $112.6 \pm 11.0$ & $+6.8 \pm 1.4^{\mathrm{a}}$ \\
\hline $\begin{array}{l}\text { Atropine (i.v.) } \\
+ \text { Peripheral end }\end{array}$ & $8.5 \pm 0.3$ & $-0.3 \pm 1.8^{\mathrm{e}}$ & $12.8 \pm 0.5$ & $-0.5 \pm 1.6^{\mathrm{d}}$ & $113.7 \pm 9.8$ & $+5.1 \pm 1.6^{\mathrm{a}}$ \\
\hline $\begin{array}{l}\text { Pentolamine (i.v.) } \\
+ \text { Central end }\end{array}$ & $7.9 \pm 0.4$ & $+8.3 \pm 0.9^{\mathrm{a}, \mathrm{d}}$ & $13.5 \pm 1.4$ & $+57.7 \pm 2.4^{\mathrm{c}}$ & $110.5 \pm 5.9$ & $-4.2 \pm 1.7^{\mathrm{a}, \mathrm{e}}$ \\
\hline $\begin{array}{l}\text { Pancronium B. (i.v.) } \\
\text { + Central end }\end{array}$ & $8.1 \pm 0.5$ & $+26.0 \pm 4.5^{\mathrm{c}}$ & $17.6 \pm 1.6$ & 0 & $110.7 \pm 8.3$ & $+12.1 \pm 6.9^{\mathrm{a}}$ \\
\hline
\end{tabular}

Values are mean \pm S.E. of dogs.

$\mathrm{R}_{\mathrm{LV}}$, Laryngeal vascular resistance; $\mathrm{P}_{\mathrm{L}}$, Intraluminal blood pressure; $\mathrm{BP}$, Mean arterial blood pressure. ${ }^{\mathrm{a}} p<0.05,{ }^{\mathrm{b}} p<0.01,{ }^{\mathrm{c}} p<0.001$ for change compared with zero effect.

${ }^{\mathrm{d}} p<0.01,{ }^{\mathrm{e}} p<0.001$ for response of stimulation after drug compared with response of stimulation without drug. 
decrease $(-7.1 \pm 7.2 \%)$ in $P_{L}$ upon stimulation of intact vagus nerve was not found to be significant. $\mathrm{BP}$, on the other hand, increased singificantly $(+13.5$ $\pm 2.3 \%$ ) in response to stimulation of intact vagus nerve (Table 1).

After bilateral cervical vagotomy, stimulation of the central end of cervical vagus nerve increased $\mathrm{R}_{\mathrm{LV}}$ significantly. The initial drop in BP was followed by a significant increase. PL on the other hand was reduced (Fig. 2A, Table 1). When the peripheral end of the cervical vagus nerve was stimulated, variable responses in $\mathrm{R}_{\mathrm{LV}}$ were observed. $P_{L}$ increased significantly. There was a significant fall in BP (Table 1).

Stimulation of recurrent laryngeal nerve. RLN was stimulated to see the individual effects of laryngeal motor nerve on same parameters. After cutting of the RLN, stimulation of the peripheral end of RLN produced a significant decrease in $\mathrm{R}_{\mathrm{LV}}$. $\mathrm{P}_{\mathrm{L}}$, on the other hand, increased significantly. There was no significant effect on BP (Table 2). Stimulation of the central end of RLN caused a significant decreases in RLV and $P_{L}$. There was no significant change in BP (Table 2).

Stimulation of superior laryngeal nerve. After cutting the SLN, stimulation of the peripheral (efferent) end decreased the $\mathrm{R}_{\mathrm{LV}}$ significantly along with a significant decrease in $P_{L}$. There was an increase in BP(Table 3). Stimulation of the central (afferent) end of the SLN caused increases in $\mathrm{R}_{\mathrm{LV}}$ and $\mathrm{P}_{\mathrm{L}}$. The response of BP was an increase (Fig. 3A, Table 3).

\section{After atropine injection}

Stimulation of cervical vagus. In order to determine the effect of parasympathetic fibers on the laryngeal vasculature, atropine was administrated. After administration of atropine (0.5-2.0 $\mathrm{mg} / \mathrm{kg}$, i.v.) stimulation of central end of a vagus nerve again caused significant increases in $R_{L V}$ and BP. The increases of both parameters were higher than that of before atropine. The decrease in PL was uneffected (Table 1).

Stimulation of recurrent laryngeal nerve. When the peripheral end of RLN was stimulated, the decrease in $R_{\mathrm{LV}}$ was less than before atropine and not significantly different from zero effect. The increase in $\mathrm{P}_{\mathrm{L}}$ was uneffected. There was also no significant change in BP (Table 2). After administration of atropine stimulation of central end of RLN abolished the decrease in $\mathrm{R}_{\mathrm{Lv}}$. $\mathrm{P}_{\mathrm{L}}$, on the other hand, increased significantly. There was no significant effect on BP (Table 2).

Stimulation of superior laryngeal nerve. When the peripheral end of SLN was stimulated after atropine administration, the increase in $\mathrm{R}_{\mathrm{LV}}$ was abolished. In contrast, the decrease in $\mathrm{P}_{\mathrm{L}}$ was virtualy uneffected. There was also a increase in BP (Table 3).

\section{After phentolamine injection}

Stimulation of cervical vagus. Vagotomy would interrupt part of the motor nerves innervating the laryngeal vasculature coming from the sympathetic nerve. Stimulation of the central end of the cervical vagus nerve would also activate this sympathetic component. To exclude, the effect of the sympathetic component, phentolamine (0.5 mg/kg, iv), an $\alpha$-adrenergic antagonist, was administrated and stimulation of central end of the cervical vagus nerve was repeated.

After phentolamine, stimulation of the central end of a vagus nerve produced a significant increase in RLv. However, the magnitude of increase was less than before phentolamine administration. Phentolamine, on the other hand, produced no significant change in the decrease in $\mathrm{P}_{\mathrm{L}}$ to the stimulation of central end of vagus. BP decreased significantly in response to stimulation of central end of the vagus after phentolamine (Fig. 2B, Table 1).

Stimulation of superior laryngeal nerve. After phentolamine, the vasoconstrictor response to stimulation of the central end of SLN was about halved. The increase of BP was abolished. There was a significant decrease in BP. The increase in $\mathrm{P}_{\mathrm{L}}$ was uneffected by phentolamine (Table 3 ).

\section{After pancuronium bromide}

Stimulation of superior laryngeal nerve. In order to determine whether somatic motor nerves 
take part in the increases of $\mathrm{R}_{\mathrm{LV}}$ and $\mathrm{P}_{\mathrm{L}}$ in response to stimulation of central end of SLN, the experimental animals were paralyzed with pancuronium bromide $(0.06-0.1 \mathrm{mg} / \mathrm{kg}$, i.v.) and artifically ventilated. Stimulation of central end of SLN caused a significant increase in $\mathrm{R}_{\mathrm{LV}}$. On the other hand, the increase in $\mathrm{P}_{\mathrm{L}}$ that was observed before pancuronium bromide was completely abolished (Fig. 3B, Table 3).

\section{Discussion}

In the present study, after bilateral cervical vagotomy, the baseline value of RLv was not affected but $\mathrm{PL}_{\mathrm{L}}$ and BP increased. Cutting of RLN and SLN did not produce a change in $R_{L v}$. These results show that no significant vagal tone is present in laryngeal vasculature of the anaesthetized dog.

According to our results, the stimulation of central ends (afferent) of the cervical vagus and SLN produced similar changes in response of $R_{\mathrm{LV}}$ which was an increase. On the other hand, the stimulation of peripheral ends (efferent) of the RLN and SLN decreased RLV.. In contrast, while the stimulation of central end of SLN increases $R_{L V}$, the stimulation of central end of RLN decreased $\mathrm{R}_{\mathrm{LV}}$.

In our previous study on tracheal circulation, we observed increases in tracheal vascular resistance, tracheal smooth muscle tone and blood pressure by stimulating the central end of the cervical vagus nerve (Şahin et al. 1987a). These results are in accordance with the present findings. Our previous studies have shown that vagal reflexes from lung $\mathrm{C}$-fiber receptors and cardiac receptors, stimulated by capsaicin and veratrine respectively, cause a laryngeal (Şahin and Güner 1992) and a tracheal vasodilation via vagus (Şahin et al. 1987c). Our present finding also rule out the possibility of a direct action of vagal stimulation on the laryngeal vasculature via cardiac and lung receptors. Furthermore, it has been investigated that intravenous administration of cholinergic agonists such as methacholine and acetylcholine in appropriate doses increase bronchial (Charan et al. 1985) and tracheal blood flow (Godden 1990).

Upon stimulation of the central end of vagus nerve, impulses arrive laryngeal vasculature through contralateral RLN and SLN. In fact, the stimulation of the peripheral ends of RLN and SLN caused laryngeal vasoconstriction by the stimulation of the motor fibers innervating laryngeal vessels. After atropine, the increase in $\mathrm{R}_{\mathrm{LV}}$ was higher. This response which occur on the stimulation of the central end of the vagus is due to the elimination of the effect of the postganglionic parasympathetic activity on the laryngeal vessels by way of SLN and contralateral RLN.

In the present study, the cervical sympathetics were not separated from the vagosympathetic trunk. For this reason, laryngeal vasoconstriction observed during the stimulation of the central end of vagus may be due to the stimulation of the sympathetic fibers. The motor nerves to the laryngeal vasculature come down by the superior laryngeal nerves and come up from the sympathetic ganglia in the chest via the recurrent nerve and the tracheoesophageal plexus (Widdicombe 1986a; Laitinen et al. 1987b). Cervical vagosympathectomy would effect neither of these pathways directly. However much of motor supply to the laryngeal muscle would be interrupted. Hence, the laryngeal vasoconstriction seen after stimulation of the central end of the cervical vagus nerve could be mediated by stimulation sympathetic fibers that come up with vagus nerve from the thoracic chain.

After $\alpha$-adrenergic antagonist phentolamine $(0.5 \mathrm{mg} / \mathrm{kg}$, i.v.), stimulation of the central end of vagus nerve still produced laryngeal vasoconstriction. However with a smaller magnitude. As expected, $\mathrm{P}_{\mathrm{L}}$ response was not affected. It is well known that, stimulation of sympathetic fibers decrease the blood flow in bronchial (Godden 1990) and tracheal vessels (Şahin et al. 1987a). When the $\alpha$-adrenoceptor agonist phenilephrine is added, flow decreases with an increase in vascular resistance in bronchial (Charan et al. 1985) and tracheal circulations (Laitinen et al. 1987a, b). In the present study, phentolamine decreased the laryngeal vasoconstriction but could not abolish it completely. This increase might be due to the release of a vasoconstrictor neuropeptide such as NPY. 
Neuropeptide tyrosine (NPY) known to modulate blood vessel diameter and smooth muscle tone has been found in many mammalian organs. Its distribution is similar to that of sympathetic nerve fibers and has been found in noradrenergic ganglion cells (Sheppard et al. 1984; Barnes 1986). In fact, immunohistochemical studies show the presence of NPY in the vicinity of superior and inferior laryngeal arteries (Lyon 2000). The abolition of the increase in BP on the stimulation of central end of vagus nerve after injection of phentolamine is due to the sympathetic effect on the central nervous system. Also, this result shows that the laryngeal circulation is more isolated than the systemic circulation.

As was indicated before, when the central end of the SLN was stimulated, significant increases in $\mathrm{R}_{\mathrm{LV}}, \mathrm{P}_{\mathrm{L}}$ and BP were observed. Laitinen et al. (1987a) suggested that the superior laryngeal nerve carries predominantly vasodilatory impulses, since electrical stimulation of it always decreases tracheal vascular resistance. This investigator had observed tracheal vasodilation and an increase in tracheal muscle tone, after stimulating the central end of the SLN (vagus intact and RLN intact). Our findings indicate the activation of efferent fibers in the contralateral SLN by afferent impulses in SLN. The results of direct stimulation of the peripheral ends of the RLN and SLN seem to agree with Laitinen's (1987a) observations.

The increase in $\mathrm{R}_{\mathrm{LV}}$ during the stimulation of central end of SLN may be due to a sympathetic effect or to the release of excitatory neurotransmitters. After phentolamine administration, the laryngeal vasoconstrictor response to stimulation of the central end of SLN was about halved. The response of BP was also abolished. As expected, the decrease in $P_{L}$ was unaffected by phentolamine. The decrease in laryngeal vasoconstriction, and total disappearance of hypertension show that the sympathetic system is responsible for the increases in $\mathrm{R}_{\mathrm{LV}}$ and BP.

According to our intraluminal laryngeal pressure recording method, the decrease and an increase in $\mathrm{P}_{\mathrm{L}}$ shows contraction of the laryngeal muscle (closing and widdening of the glottic orifice). Laryngeal muscle contraction as a result of vagal stimulation is the expected result (Stransky et al. 1973). Most previous studies suggested that stimulation of vagus nerves or electrical field stimulation of airway tissue results in contraction of lower airways muscles which are blocked by atropine (Widdicombe 1986a, b). These responses are also mimicked by drugs such as acethylcholine, methacholine and enhanced by anticholinesterase (Widdicombe 1986a; Laitinen et al. 1987a). As is well known, the striated muscles of the larynx have a cholinergic innervation through the recurrent and, to a smaller extent, the superior laryngeal nerves. Hence, cholinergic effects are mediated via nicotinic receptors on the striated fiber, and cholinergic control of the laryngeal structures can therefore not be assessed by the use of antimuscarinic drugs (Widdicombe et al. 1991). Laryngeal tone can be affected by mediators acting directly or indirectly through reflexes from the upper and lower airways (Widdicombe et al. 1991; Kobler et al. 1994). This is why, in our study, after atropine administration the response of $P_{L}$ was uneffected on the stimulation of central end of the vagus.

The increase in $P_{L}$ obtained on the stimulation of the peripheral end of cut vagus nerve could be mediated by motor fibers running through the RLN. As is well known, the recurrent laryngeal nerve, which is responsible for the motor innervation of the larynx, leaves vagus at the upper thoracic region and goes to the larynx (Stransky et al. 1973; Widdicombe 1986a, b). The decrease in BP depends on the general cardiovascular response.

After atropine administration, the decrease in $\mathrm{R}_{\mathrm{LV}}$ by the stimulation of the central end of RLN was abolished. These results suggest that RLN include afferent parasympathetic fibers. When the peripheral end of RLN was stimulated in order to the determine motor effects of RLN on laryngeal vascularity and muscle tone, the decrease in $\mathrm{R}_{\mathrm{LV}}$ was observed more prominently. There was an increase in $\mathrm{P}_{\mathrm{L}}$. After atropine, the increase in la- 
ryngeal muscle tone did not change, as expected, while the response in $\mathrm{R}_{\mathrm{LV}}$ decreased profoundly. It is known that the RLN is a mixed type of nerve, containing parasympathetic and sympathetic nerve fibers (Widdicombe 1986a). The parasympathetic motor fibers (vasodilator component) in the RLN were observed to be effective on the laryngeal vascularity. The significant decrease in $R_{L v}$ after stimulation of the peripheral end of SLN, which is the afferent nerve of larynx, suggests the presence of motor fibers in this nerve which innervate the laryngeal vasculature. The absence of any significant changes in RLV after atropine administration indicate that SLN also include parasympathetic efferent fibers which innervate laryngeal vessels. The increase in BP may be mediated by the effect of non-neural substances such as NPY.

In this situation, the laryngeal vasoconstriction that was observed during stimulation of the central end of the vagus and nonsignificant laryngeal vasoconstriction obtained during stimulation of the peripheral end of the vagus imply that motor fibers causing laryngeal vasoconstriction are not present with in the recurrent laryngeal nerve. This finding also indicates that other mechanisms are responsible for laryngeal vasoconstriction in response to stimulation of the central end of the vagus.

It may be thought that laryngeal muscle contraction may have a mechanical effect on the vasculature and may compress the blood vessels in the laryngeal muscles. Hence, it may cause an increase in RLv. However, in the present study, on the stimulation of both ends of RLN, opposite responses in $R_{L V}$ and $P_{L}$ were observed. Therefore, our results show no evidence of this effect.

After pancronium bromide, the abolition of the increase in $\mathrm{P}_{\mathrm{L}}$ and the persistence of an increase in $R_{\mathrm{LV}}$ on the stimulation of central end of SLN indicate that the changes in $\mathrm{R}_{\mathrm{LV}}$ are not passively mediated by laryngeal muscle contraction or relaxation.

After cutting of vagus and RLN, the stimulation of central end of SLN again increased $R_{L V}$. The persistence of laryngeal vasoconstriction after sympathetic antagonist suggests that nonadrenergic system may be effective on $\mathrm{R}_{\mathrm{LV}}$.

In conclusion, our findings suggest that, parasympathetic motor fibers in the RLN and SLN are effective for the laryngeal vascularity. On the other hand, the both vagal and SLN afferents activate vasoconstrictor pathways to the laryngeal circulation and systemic circulation via partly sympathetic system. Nonadrenergic system may be also responsible for laryngeal vasoconstriction. Furthermore, there is no resting vagal tone in the laryngeal vascularity of anaesthetized animals.

\section{References}

Barnes, P.J. (1986) Neural control of human airway in health and disease. Am. Rev. Respir. Dis., 134, 1289-1314.

Bradley, R.M. (2000) Sensory receptors of the larynx. Am. J. Med., 108, 47-50.

Brouillette, R.T. \& Thach, B.T. (1979) A neuromuscular mechanism maintaining extrathoracic airway patency. J. Appl. Physiol., 46, 772-779.

Charan, N.B., Turk, G.M. \& Ripley, R. (1985) Measurement of bronchial arterial blood flow and bronchovascular resistance in sheep. J. Appl. Physiol., 59, 305-308.

Dylewska, K., Şahin, G. \& Widdicombe, J.G. (1993) Asymmetric reflex responses of the nasal and tracheal vasculatures of the dog. J. Appl. Physiol., 75, 2157-2161.

Godden, D.J. (1990) Reflex and nervous control of the tracheobronchial circulation. Eur. Respir. J., 3, 602-607.

Güner, I. \& Şahin, G. (1993) The effects of non-neural mediators on the dog laryngeal circulations and muscle tone. Eur. Respir. J., 6, 402.

Hisa, Y., Koike, S., Tadaki, N., Bamba, H., Shogaki, K. \& Uno, T. (1999) Neurotransmitters and neuromodulators involved in laryngeal innervation. Ann. Otol. Rhinol. Laryngol. Suppl., 178, 3-14.

Jodkowski, J.S. \& Berger, A.J. (1988) Influences from laryngeal afferents on expiratory bulbospinal neurons and motoneurons. J. Appl. Physiol., 64, 1337-1345.

Kobler, J.B., Datta, S., Goyal, R.K. \& Benecchi, E.J. (1994) Innervation of the larynx, pharynx, and upper esophageal sphincter of the rat. J. Comp. Neurol., 349, 129-147.

Laitinen, L.A., Laitinen, M.A. \& Widdicombe, J.G. 
(1987a) Parasympathetic nervous control of tracheal vascular resistance in the dog. $J$. Physiol., 385, 135-146.

Laitinen, L.A., Laitinen, M.A. \& Widdicombe, J.G. (1987b) Dose-related effects of pharmacological mediators on tracheal vascular resistance in dogs. Br. J. Pharmacol., 92, 703-709.

Lyon, M.J. (2000) Nonadrenergic innervation of the rat laryngeal vasculature. Anat. Rec., 259,180-188.

Şahin, G., Webber, S.E. \& Widdicombe, J.G. (1987a) Nervous control of tracheal vascular resistance. Clin. Respir. Physiol., 23, 384.

Şahin, G., Webber, S.E. \& Widdicombe, J.G. (1987b) Lung and cardiac reflex actions on the tracheal vasculature in anaesthetized dogs. J. Physiol., 387, 47-57.

Şahin, G., Webber, S.E. \& Widdicombe, J.G. (1987c) Chemical control of tracheal vascular resistance in dogs. J. Appl. Physiol., 63, 988-995.

Şahin, G. \& Güner, I. (1992) The effects of lung and cardiac reflex on laryngeal vascular resistance and muscle tone. Eur. Respir. J., 5, 457.

Şahin, G., Oruç, T. \& Güner, I. (1999) Chemical control of laryngeal vascular resistance in anesthetized dogs. J. Basic Clin. Physiol. Pharmacol., 10, 273-285.

Sant'Ambrogio, G. \& Sant'Ambrogio, F.B. (1996) Role of laryngeal afferents in cough. Pulm. Pharmacol., 9, 309-314.

Sataloff, R.T., Spiegel, J.R., Hawkshaw, M. \& Rosen, D.C. (1993) Gastroesophageal reflux laryngitis.
ENT. J., 72, 113-114.

Sheppard, M.N., Polak, J.M. \& Allen, S.R. (1984) Neuropeptide tyrosine (NPY): a newly discovered peptide is present in the mammalian respiratory tract. Thorax, 39, 326-330.

Shiba, K., Yoshida, K., Nakajima, Y. \& Konno A. (1997) Influences of laryngeal afferent inputs on intralaryngeal muscle activity during vocalization in the cat. Neurosci. Res., 27, 85-92.

Stransky, A., Szereda-Przestaszewska, M. \& Widdicombe, J.G. (1973) The effects of lung reflexes on laryngeal resistance and motoneurone discharge. J. Physiol., 231, 417-438.

Widdicombe, J.G. (1986a) Reflex from the upper respiratory tract. In: Handbook of Physiology: The Respiratory System II, edited by N.S. Cherniack \& J.G., Widdicombe, American Physiological Society, Washington D.C., pp. 363-394.

Widdicombe, J.G. (1986b) Sensory innervation of the lungs and airways. Brain Res., 67, 49-64.

Widdicombe, J.G. (1990) Comparison between the vascular beds of upper and lower airways. Eur. Respir. J., 3 , 564-571.

Widdicombe, J.G., Karlson, J.A. \& Barnes, P.J. (1991) Cholinergic mechanisms in bronchial hyperresponsiveness and asthma. In: Asthma Its Pathology and Treatment, edited by M.A. Kaliner, P.J. Barnes, C.G.A. Persson, Marcel Dekken, Inc, New York, Basel, Hong Kong, pp. 327-255.

Widdicombe, J. (2001) Airway receptors. Respir. Physiol., 125, 3-15. 